beginning to feel dissatisfied with the role of science and its present applications to human welfare, and that a material change, if not a complete break, will have to be made with the present economic system before science can be fully utilized. Concern at the insecurity of their own position in the immediate future is leading scientific workers to the view that a new type of scientific organization, based.on the experience of the trade unions in the defence of the economic and cultural interests of large masses of the population, is becoming necessary.

\section{The Earthquake in Turkey}

As the railway between Sivas and the ruins of Erzinjan has now been repaired, it is possible to add a few more details concerning the Erzinjan earthquake of December 27, 1939 (see NATURE of Jan. 6, p. 13). From Ankara to Sivas and Tokat the damage has been done chiefly to the old and badly constructed buildings made from inferior material, whilst the better ferro-concrete public buildings of recent construction have escaped with cracks and minor damage; but from Tokat and Sivas to Erzinjan there has been practically complete destruction of old and new. The only 'oasis' of lesser damage thus far recorded has been at Kemah near Erzinjan, where some buildings still stand, though 548 buildings were wrecked and nearly 150 casualties caused. It appears probable that Kemah was built on more solid rock than the other towns in the area of approximately 15,000 square miles affected.

In the mountainous district between Amasya and Tokat there are ground fissures 12 yards wide, out of which are said to issue smoke and sulphur fumes and also jets of boiling water. There is as yet no direct news of some five hundred villages to the east of Erzinjan, although efforts are being made to reach them through a countryside covered to a depth of $12 \mathrm{ft}$. in snow. At Niksar, a rock pinnacle fell on the town, doing much damage, and there were few survivors in this place or in fourteen of the neighbouring villages, whilst on the Black Sea coast the towns of Kerasun and Ordu are reported to have suffered the greatest damage.

At Kew Observatory the first waves to arrive did so at 0 h. $3 \mathrm{~m}$. 26s. G.M.T. and the maxima exceeded the limits of registration, the ground movement being greater than one millimeter in amplitude. Several severe after-shocks have occurred as well as hundreds of smaller ones. On January 1 there were seven severe after-shocks at Erzinjan, and a violent shock at 7 a.m. local time at Bergama in the west of Turkey. On January 2 at Yozgad there was a strong shock and 190 houses collapsed, though no casualties are reported. The after-shocks appear now to be decreasing in strength and number. Although the after-shock of January 1 was at Bergama, it is yet uncertain whether the floods in the Brusa and Smyrna districts of Turkey and in the Bilecik Valley (River Sakaria) had anything to do with changes in topography attendant on the earthquakes, nor whether the Kemal Pasha Dams and numerous river bridges were destroyed by the shocks or by the floodwaters, but if the meteorological conditions in the area did not cause the floods, they certainly enhanced them considerably.

\section{Other Recent Earthquakes}

ON December 21, San José (Costa Rica) suffered the most severe earthquake it has known since 1923. Buildings were cracked, including the cathedral, though no casualties are reported. The shock was recorded at Manila, at De Bilt (Holland), where the $P$ wave arrived at $2 \mathrm{lh} .7 \mathrm{~m}$. 10s. G.M.T., and at Kew, where the first of three shocks in rapid succession arrived at $21 \mathrm{~h} .6 \mathrm{~m}$. 51s. G.M.T., the maximum ground amplitude at Kew being $0.42 \mathrm{~mm}$. On December 22, considerable damage is reported to have been caused by earthquake shocks in Costa Rica, though no loss of life or other casualties are reported. These shocks were possibly after-shocks of the earthquake which rocked San José on December 21.

On December 22 also severe earthquake shocks were experienced in the South Sea islands of Molucca. On December 23 and 24 earthquakes and landslides, which were probably caused by the earthquakes. occurred in Java in the East Indies. In addition to the Anatolian earthquake of December 27, further shocks were registered at Kew Observatory on December 25 (2), December 28 and December 29. Further news concerning all these shocks is awaited from the areas concerned and from other seismological observatories. On January 2, early in the day, an earthquake shock was perceptible on the Ionian Island of Zante (Greece), though no damage or loss of life has been reported.

\section{Potatoes in War-time}

Potatoes are one of the most valuable sources of human and animal food in war-time, and it is of the greatest national importance that both the acreage devoted to this crop shall be increased and that the maximum yields shall be obtained. Questions of quality, colour and shape must now take second place and yield be the all-important aim of the grower. The National Institute of Agricultural Botany, Cambridge, has just issued a war-time edition of its Farmer's Leaflet No. 3, in which useful information to this end is supplied. Emphasis is laid on the necessity for using healthy seed, as otherwise attention to cultivation, manuring, etc., is of little value. A number of varieties are recommended for both early and main crops; but it is pointed out that to lift potatoes in an unripe condition is an unwarranted waste of tonnage in a time of emergency. As regards choice of varieties, most of those commonly grown are still recommended, but King Edward should be replaced by a heavier cropping kind such as Arran Banner, Arran Consul, Kerr's Pink, Majestic or Redskin.

The use of unsaleable potatoes for animal feeding is the subject of "Growmore" Leaflet No. 10, issued by the Ministry of Agriculture. All potatoes, whether to be used raw or cooked, should be washed before feeding, or digestive trouble may result. Raw potatoes 